\title{
TRIP MATRIX ESTIMATION FROM TRAFFIC COUNTS USING CUBE
}

\author{
Subha Nair ${ }^{1}$, Nisha Radhakrishnan ${ }^{2}$, Samson Mathew ${ }^{3}$ \\ ${ }^{1}$ Post Graduate Student, ${ }^{2}$ Assistant Professor, ${ }^{3}$ Professor, Department of Civil Engineering, National Institute of \\ Technology Trichy, Trichy- 620015, India \\ subhanair_89@yahoo.com,nisha@nitt.edu,sams@nitt.edu
}

\begin{abstract}
This paper presents a distinguished method of integrating Direct and Indirect Methods of estimating O-D Matrix. Direct method includes household and demographic data, whereas indirect method includes traffic counts. CUBE is highly efficient transport modeling software whereas ArcGIS is a geospatial tool which gives the geographic information of the land. The various factors influencing the trip generation, considered in this paper are household data like employment, population, income and average household occupancy and residential density. The secondary data are collected from the municipal offices and other local government bodies of Tiruchirappalli district of Tamil Nadu. The traditional four-step modeling is done in CUBE, using these factors, to obtain a priori $O-D$ matrix. Further, traffic counts in the concerned network are determined using traffic surveys in major arterial roads in Tiruchirappalli city. For updating the existing Origin-Destination matrix using link volumes the gradient descent approach has been used. In this paper a unique attempt has been made to script a bi-level program in the CUBE software. The traffic counts are used to remodel in Cube using to get an updated matrix.
\end{abstract}

Keywords: Bi-level programming, CUBE 6.0, Gradient method, Link Volume, O-D matrix, Regression, Travel demand. $* * *$

\section{INTRODUCTION}

Traffic Demand in an area can be represented by an origindestination matrix which is essentially a table containing the number of trips from each origin to each destination in the area (Abrahamsson $\mathrm{T}$, 1988). Origin-destination (O-D) matrices are of vital importance for traffic management and control as well as transportation systems operation, design, analysis, and planning in the longer term. These matrices contain information about the spatial and temporal distribution of activities between different traffic zones in an urban area. Estimating O-D Matrix from traffic flow data collected on road links is a tool commonly used to produce O-D Matrices when existing information is out-of-date or incomplete. It is also less labour intensive than traditional methods for deriving O-D Matrices, such as O-D survey method using home or roadside interviews.

There is some software which can estimate O-D Matrix but it is always wise to use coded algorithms which can be flexible to the type of data available in the study area. Bi-level programming is hierarchical optimization problem, where the constraints of one problem are defined in part by a second parametric optimization problem. The priori matrix to be input into the bi-level programming can be obtained from the Software CUBE 6.0 which is highly efficient coded transportation planning software. In this thesis a unique attempt has been made to script a bi-level program in the CUBE software. The result will be a highly efficient and precise O-D Matrix for Tiruchirappalli City.

\section{ESTIMATION OF ORIGIN-DESTINATION MATRIX}

\subsection{Introduction}

The Origin-Destination (O-D) matrix estimation problem is to find an estimate of some travel demand between pairs of zones in a region. The OD matrix is difficult and often costly to obtain by direct measurements/interviews or surveys, but by using traffic counts and other available information one may easily obtain a reasonable estimate. Virtually all models for OD matrix estimation use prior information on the OD matrix. The prior information might be expressed in terms of a target OD matrix.

\subsection{Estimation of Origin-Destination Flows from}

\section{Traffic Counts}

The method of estimating O-D trip matrix from traffic counts is reversely estimating the O-D trip matrices from the link traffic counts, making an assumption that certain relation exists between the data of the future O-D trip matrices, which cannot be observed at once, and the present observation of the link traffic counts (Bera. S, 2011). This basis concept can be described as follows:

$$
\mathrm{Va}=\sum \mathrm{i} \sum \mathrm{j} \text { paijTij }
$$

Where; Va = flow on link ' $a$ ' in the network, $\mathrm{Tij}=$ number of trips between zone $\mathrm{i}$ and zone $\mathrm{j}$, 
paij = proportion of trips from origin $\mathrm{i}$ to destination $\mathrm{j}$ which uses link ' $a$ ',

$\mathrm{a}=$ link considered,

$\mathrm{i}=$ origin zone,

$\mathrm{j}=$ destination zone,

\section{METHODOLOGY}

The travel demand in the study area is dependent on many factors which influence the number of trips generated from a region. In the state-of-art, it is assumed that the trips are originating and terminating towards the zone center. The zonal characteristics, therefore, play an important part in the study.

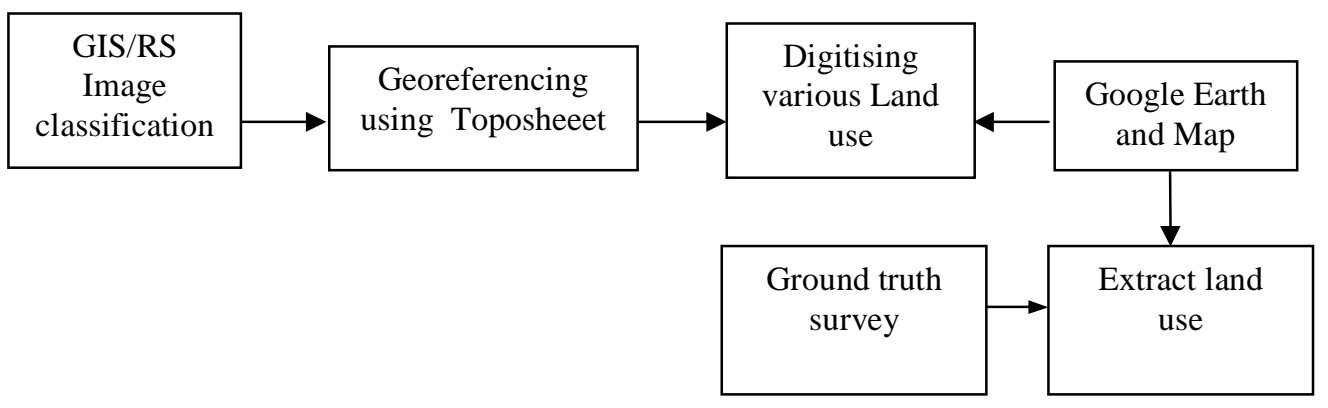

Methodology adopted for extraction of land-use

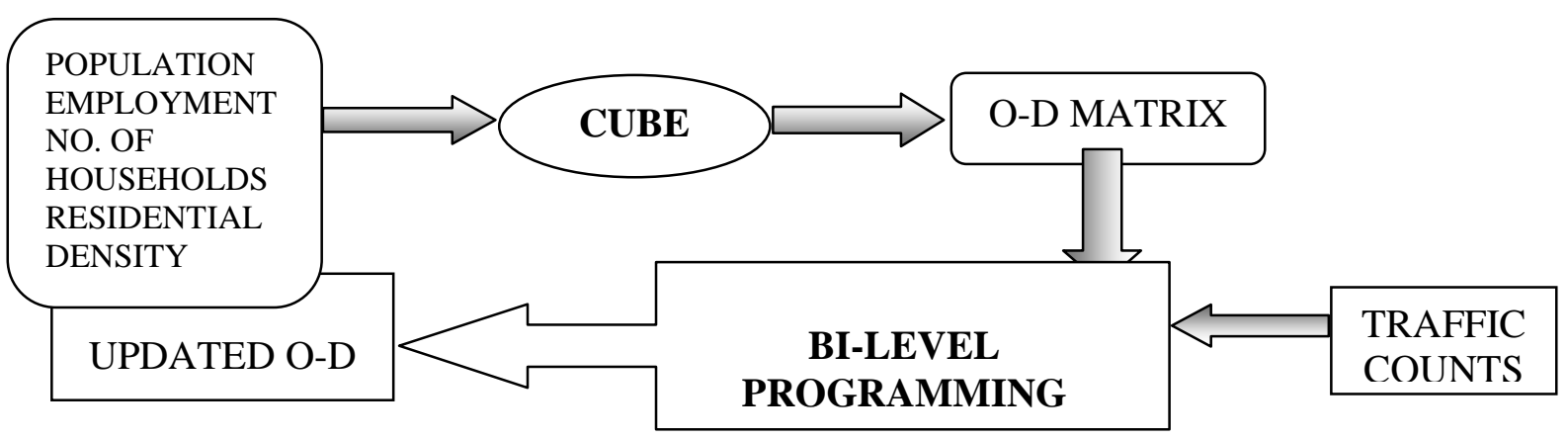

Methodology adopted for estimation of O-D matrix from bi-level programming

\section{SOFTWARE USED}

\subsection{Arc GIS 9.2}

Arc GIS has a high-level geographic data model for representing spatial information as features, rasters, and other spatial data types. Arc GIS supports an implementation of the data model for both file systems and DBMSs. The file-based models include GIS datasets, such as coverages, shape files, grids, images, and Triangulated Irregular Networks (TINs). Arc GIS enables a large volume of imagery to be made quickly accessible to a wide range of applications and users.

\subsection{Cube 6.0}

The CUBE software suite is a comprehensive set of modules that support transportation planning, including transportation forecasting and system analysis. CUBE integrates the best in modeling methods with the best in graphics technology for the study of transportation systems. With CUBE, you can generate decision-making information quickly using powerful modelling and GIS techniques, statistics and comparisons, high-quality graphical output, and a variety of reporting methods.

\section{STUDY AREA}

The study area is Tiruchirappalli town, Tamilnadu (Fig 1), one of the famous historical and cultural cities in India. The spatial extend of the study area is between $10^{\circ} 44^{\prime} 46^{\prime \prime} \mathrm{N}$ to $10^{\circ} 52^{\prime}$ $46^{\prime \prime} \mathrm{N}$ Latitude and $78^{\circ} 39^{\prime} 11^{\prime \prime}$ to $78^{\circ} 44^{\prime} 13^{\prime \prime}$ E Longitude. Tiruchirappalli city consists of 60 wards (4 zones). Each zone is divided into 15 wards. Tiruchirappalli city consists of 60 wards ( 4 zones). Each zone is divided into 15 wards.

\subsection{Data Source}

CARTOSAT-1 or IRS P5 (Indian Remote Sensing Satellite) is a state-of-the-art remote sensing satellite built by ISRO which is mainly intended for cartographic applications. 


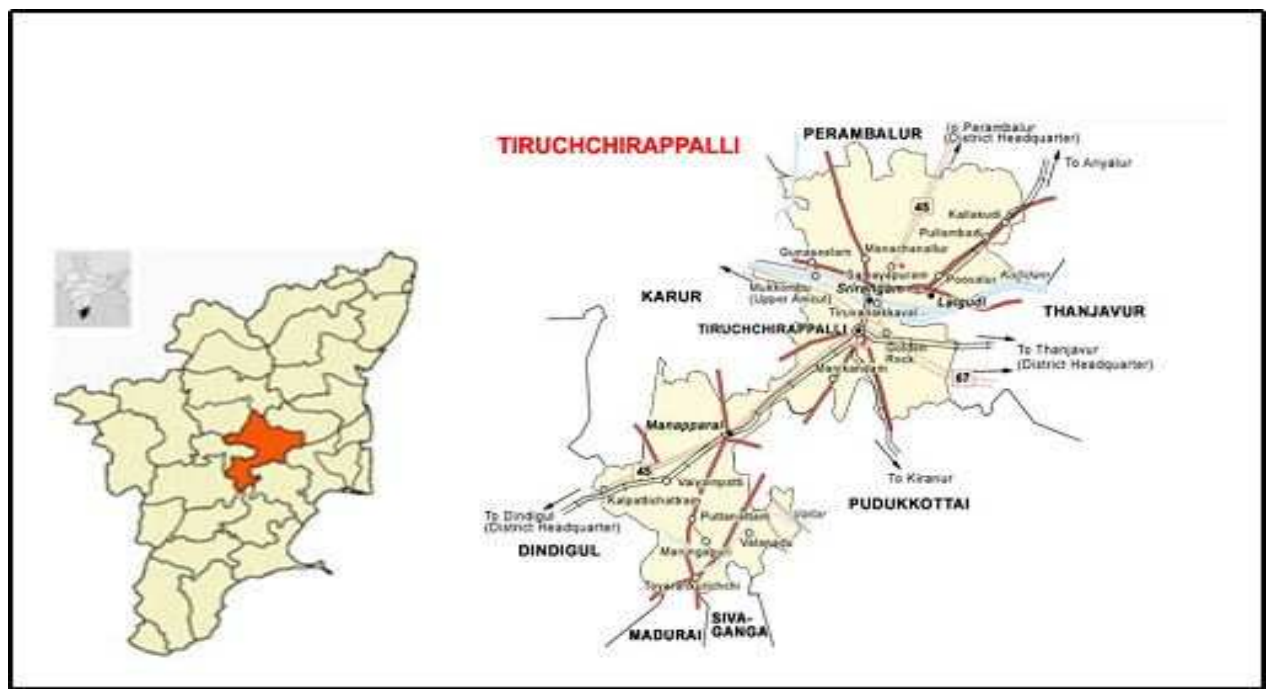

Fig. 1 Tiruchirappalli District

\subsection{Demographic Data and Network Details}

The Demographic data and other secondary data were obtained from the Tiruchirappalli Municipal Corporation. The network details including the Name of Road, Class of Road, Speed etc. are collected. All these are required to be input into the modeling software for obtain a compatible matrix.

\subsection{Land Use Classification}

The various land use was identified using Google Earth maps and similarly in Arc GIS 9.2 and digitized simultaneously. The characteristics of the digitized areas were cross-checked using ground truth analysis. The total area of each land use was summed up and the residential density was determined in persons per sq. $\mathrm{km}$. This is used as a measure in determining the travel demand of an area (Aswathy R, 2011). But as a fact residential density by itself cannot be a determining factor in trip generation. Depending upon the characteristic and accessibility index of an area the residential density may differ ( Maneesha M, 2010). Fig .(2)

\begin{tabular}{|c|c|c|c|c|c|c|c|}
\hline \multicolumn{6}{|c|}{ 回 Attributes of boundary } & \multicolumn{2}{|c|}{ 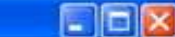 } \\
\hline & OВJЕСТ̈: & SHAPE ${ }^{*}$ & LU_Class & SHAPE_Length & SHAPE_Area & & $\wedge$ \\
\hline D & 1 & Polygon & Residential & 3679.934358 & 237235.383082 & & \\
\hline & 2 & Polygon & Others & 594.944786 & 15219.545496 & & \\
\hline & 3 & Polygon & Others & 535.418203 & 3651.829732 & & \\
\hline & 4 & Polygon & Others & 396.822846 & 5369.030696 & & \\
\hline & 5 & Potygon & Others & 161.172115 & 1449.911089 & & \\
\hline & 6 & Polygon & Others & 4247390044 & 207933.131547 & & \\
\hline 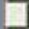 & 7 & Polygon & Others & 967.91806 & 18002.563944 & & \\
\hline & 8 & Polygon & Cominercial & 478.058425 & 7229.113518 & & \\
\hline & 9 & Polygon & Agricutural land & 1385.447246 & 65226.315521 & & \\
\hline & 10 & Potygon & Conmercial & 510.838883 & 10970.129253 & & \\
\hline & 11 & Polygon & Commercial & 471.349797 & 9196.783268 & & \\
\hline & 12 & Polygon & Residertial & 149.563362 & 1431.487523 & & \\
\hline 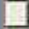 & 13 & Polygon & Residential & 226.868218 & 1613.803199 & & \\
\hline & 14 & Potygon & Residential & 62.992719 & 208.390917 & & \\
\hline & 15 & Polygon & Residertial & 7589208 & 328.267631 & & \\
\hline & 16 & Polygon & Residential & 84.319921 & 249.482233 & & \\
\hline & 17 & Polygon & Residertial & 56.568674 & 169.057156 & & \\
\hline & 18 & Polygon & Residential & 99.770598 & 533.434957 & & \\
\hline & 19 & Polygon & Residertial & 7908264 & 341.39693 & & \\
\hline & 20 & Polygon & Residertial & 40.568741 & 91914698 & & \\
\hline & 21 & Polygon & Residertial & 46.930006 & 114.893213 & & \\
\hline & 22 & Polygon & Residertial & 52.891351 & 172.339503 & & $\sim$ \\
\hline & Record: 14 & 4 & $1, \|$ & All Selected & Records (0 out of 59 Selected) & Options - & \\
\hline
\end{tabular}

Fig. 2 Attribute table for various Land- use of ward 15 


\section{TRAVEL DEMAND PARAMETERS}

Trip generation models relate trip generation rates to land-use and household characteristics. The physical and demographic characteristics of the area include: employment, population, and density. There are at least two approaches in terms of data aggregation in trip generation models: aggregate trip generation models and disaggregate trip generation models. In aggregate models, data at a given geographic level, such as neighbourhood or city, are used. In disaggregate models, data at the household or individual levels are used.

Densely population residential areas will generate large numbers of trips in the morning peak period. Industrialised areas will attract large numbers of trips in the morning peak.

\section{TRIP GENERATION EQUATIONS}

Dependent variable $=$ no. of trips generated per person per zone for different trip purposes

Independent variables $=$ land use and socio-economic factors which are considered to influence trip making. The equations for the trip attracted and produced were as follows :

Trips produced $=0.9098 \times$ Households $+0.2556 \times$ Student population $+0.2213 \times$ Total population $+9769.9162 \times$ Special zone $+11.2146 \times$ Residential Density

(2)

Trips attracted $=0.1559 \times$ Employment $+10014.0814 \times$ Special zone (3)

\section{Zonal Least Squares Regression Analysis:}

Multiple correlation coefficients R2 measures the goodness of fit between the regression estimates and the data. In this study the $\mathrm{R} 2$ value obtained is 0.87 which shows the given equation has a good fit.

\subsection{Trip Generation in Cube 6.0}

Trip Generation: Estimates the total daily demand for travel (typically in person trips per day) arising from various urban activities (Work/ Education/ Recreation/ Other).

\section{Inputs}

Socio economic/demographic data for all zones

Trip production and attraction equations

Outputs

Production Attraction table

Methods

User specified linear or non-linear P/A equations

\subsection{Trip Distribution in Cube 6.0}

Distribution program processes zonal trip productions/attractions, inter-intra zonal travel impedances/ friction factors and generates a matrix of trip interchanges called the PA matrix.

Inputs

Balanced zonal productions \& attractions

Impedance Matrix and friction factor table.

Outputs

Production Attraction matrix

Methods

Gravity model method is implemented.

Friction factor table

Gravity model procedures produce a trip table for each trip purpose. The trip table produced by these procedures can be factored to represent the proportion of travel projected to occur over an entire day, or any specific time period that has to be investigated.

\subsection{Impedance Matrix}

One of the major inputs to a gravity model trip distribution model is the Highway Impedance matrix. In determining the travel impedance (the path of least resistance between each pair of zones), travel times, distance and/or tolls are summed up for the links between each zone pair and the results are stored in a zone-to-zone travel impedance matrix. In this study the Impedance Matrix can be generated from the software CUBE using the Friction Factor table and Network file as input.

\subsection{Conversion of P-A Matrix to O-D Matrix}

To convert PA matrix (Trip Ends) into equivalent O-D matrix which gives trip interchanges in terms of person trips per day between every pair of zones.

\section{GRADIENT BASED APPROACH FOR MATRIX UPDATION}

\subsection{Introduction}

The gradient method for adjusting a single class origindestination matrix by using observed flows is extended to consider a reference matrix and to adjust simultaneously the O-D matrices. In order to maintain the structure of the O-D matrices that are adjusted, it is highly desirable to include a demand term in the objective function of the adjustment model (Spiess, H., 1990). Weightages are given to the link term and the demand term which together constitute the objective function. The minimisation of the objective function with a negative gradient and a calculated step length forms the constraint for function.

\subsection{Problem Definition}

The nodes of the road network is denoted $n$, where $n \in N$ and the links are denoted a, where $\mathrm{a} \in \mathrm{A}$, considering $\mathrm{n}$ is the set of nodes and a is the set of links. The set of O-D pairs is denoted by $\mathrm{I}$ and it is convenient to refer to the O-D pair with index $\mathrm{i}=$ $(p, q), i \in I$ where $p$ (origin), $q$ (destination) $\in \mathrm{N}$. The various 
classes of traffic are taken as single class denoted as $\mathrm{m}$. the demand for travel by user class $\mathrm{m}$ for the O-D pair I is denoted gi . A is the set of links with available class $m$. The O-D demands may use paths $\mathrm{Ki} \in \mathrm{K}$, where $\mathrm{K}$ is the set of all routes and $\mathrm{k}$ the path index. The path flow of class $\mathrm{m}$ on the route $\mathrm{k}$ is denoted hk and gives rise to link flows va on link a, a€A. The total link flow va on link a is the sum of all route flow va $=\sum$ va. The adjusted demand class should yield assigned flows which are close to the observed link flows and remain close of the original values gi for all the O-D pairs I (Javier, D.,2004).

\subsection{Solution Algorithm}

A compact formulation of the bi-level (or mathematical programming with equilibrium constraints) single-class O-D adjustment problem is given by the following algorithm (Noriega,Y.,2009):

Step 0: Initialization. Iteration $1=0$

Step 1: Single-class assignment. Single-class assignment of demand $\mathrm{g}^{1}$ (for all $\mathrm{m}$ ) to obtain link volumes $\mathrm{v}_{\mathrm{a}}{ }^{1}$ for $\mathrm{a} \in \mathrm{A}$

Step 2: Link derivatives and objective function. Computation of the link derivatives $\left(\mathrm{v}_{\mathrm{a}}{ }^{1}-\mathrm{v}_{\mathrm{a}}{ }^{1}\right)$ for $\mathrm{a} \in \mathrm{A}$, and the objective function :

$\alpha / 2 \sum_{\mathrm{k} \in \mathrm{K}} \sum_{\mathrm{a} \epsilon \mathrm{A}}\left(\mathrm{v}_{\mathrm{a}}{ }^{\mathrm{k}}(\mathrm{g})-\mathrm{v}_{\mathrm{a}}{ }^{\mathrm{k}}\right)^{2}+(1-\alpha) / 2 \sum_{\mathrm{k} \in \mathrm{K}} \sum_{\mathrm{i} \in \mathrm{I}}\left(\mathrm{g}_{\mathrm{i}}{ }^{\mathrm{k}}\right)^{2}$

If the maximum number of iterations $\mathrm{L}$ is reached go to Step 7 Step 3: Assignment to compute the gradient matrix. Carry out single-class assignment with path analysis to compute the gradient matrices, then add demand term

$\Delta \mathrm{Z}(\mathrm{v}, \mathrm{g})^{1}=\mathrm{dZ}(\mathrm{v}, \mathrm{g})^{1} / \mathrm{dg}_{\mathrm{i}}{ }^{1}=\alpha \sum_{\mathrm{k} \in \mathrm{K}} \mathrm{p}_{\mathrm{k}}{ }^{1} \sum_{\mathrm{a} \in \mathrm{A}} \delta_{\mathrm{ak}}\left(\mathrm{v}_{\mathrm{a}}{ }^{1}-\mathrm{v}_{\mathrm{a}}{ }^{1}\right)+(1-\alpha)$ $\left(\mathrm{g}_{\mathrm{i}}{ }^{1}-\mathrm{g}_{\mathrm{i}}{ }^{1}\right)$

Step 4: Assignment to obtain the derivatives. Carry out assignment to obtain the descent direction

$\mathrm{y}_{\mathrm{a}}{ }^{1}\left(\mathrm{~d}_{\mathrm{i}}{ }^{1}\right)=-\sum_{\mathrm{i} \in \mathrm{I}} \mathrm{g}_{\mathrm{i}}{ }^{1} \Delta \mathrm{Z}(\mathrm{v}, \mathrm{g})^{1}\left(\sum_{\mathrm{k \in K}}{ }^{1} \delta_{\mathrm{ak}}{ }^{1} \mathrm{p}_{\mathrm{k}}{ }^{1}\right)$

Step 5: Update of the demand matrices.

Optimal step length:

$$
\Lambda^{1} *=\frac{\alpha \sum_{\mathrm{a} \in \mathrm{A}}\left(\mathrm{v}_{\mathrm{a}}-\mathrm{v}_{\mathrm{a}}{ }^{1}\right) \mathrm{y}_{\mathrm{a}}{ }^{1}+(1-\alpha) \sum_{\mathrm{iEI}}\left(\mathrm{g}_{\mathrm{i}}-\mathrm{g}_{\mathrm{i}}{ }^{1}\right)^{2} \mathrm{~d}_{\mathrm{i}}{ }^{1}}{\alpha \sum_{\mathrm{a} \in \mathrm{A}}\left(\mathrm{y}_{\mathrm{a}}{ }^{1}\right)^{2}+(1-\alpha) \sum_{\mathrm{i \epsilon I}}\left(\mathrm{d}_{\mathrm{i}}{ }^{1}\right)^{2}}
$$

Update of the demand matrix:

$\mathrm{g}_{\mathrm{i}}{ }^{1+1}=\mathrm{g}_{\mathrm{i}}{ }^{1}+\min \left(\kappa^{1^{*}}, 1\right)^{*} \Delta \mathrm{Z}(\mathrm{v}, \mathrm{g})^{1}$

Step 6: Iteration counter. Update the iteration counter $1=1+1$ and return to Step 1

Step 7: End

\subsection{Testing of Program Using Hypothetical Network in Matlab}

Using MATLAB a hypothetical network was created and then the Gradient descent approach was applied to it.

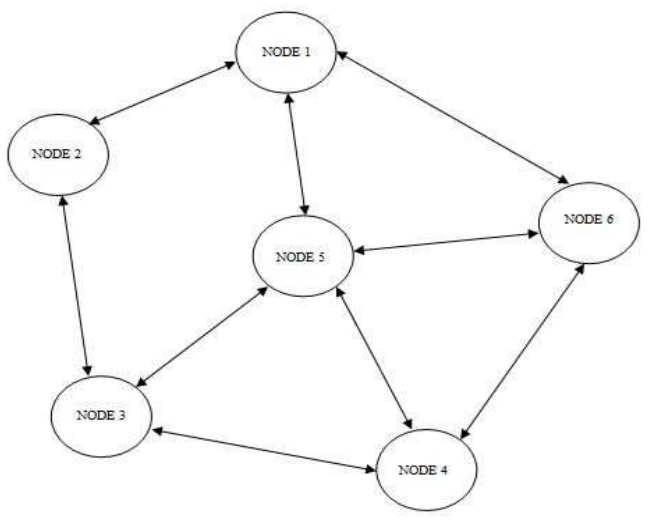

Fig. 5 Hypothetical Network 1

\section{Comparison between Target and Obtained volumes}

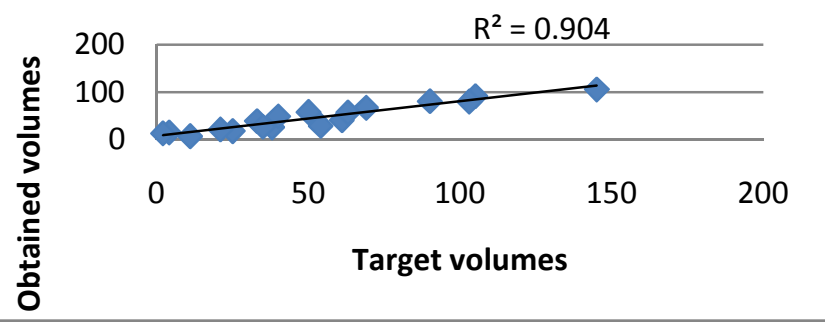

Fig. 6 Graph showing Target and Obtained volumes for network 1

\subsection{Application of Program to Real Network}

The work flow of model in CUBE consists of the following:

1. Gather and code data- Transportation networks, roadway centerlines, intersection definitions

2. Define TAZ boundaries- here 60 wards are considered as TAZs and summarize demographic and economic factors ( households and employment ) by zone

3. Define model functions- Obtain travel behavior and survey the traffic proportions and network details

4. Specify, estimate and calibrate mathematical relationships using statistical and regression tools and methods

5. Link data and processes with interface- Sequence steps and link common data files

6. Creation of catalog, to run, review, revise as needed 


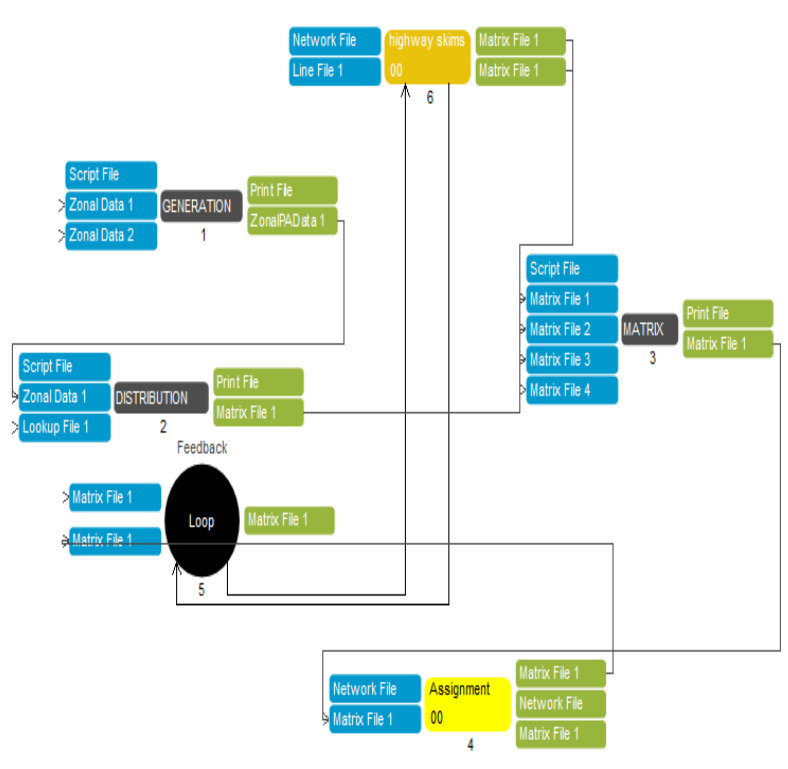

Fig. 7 Complete travel demand modeling in CUBE

\section{RESULTS}

From the model proposed in the study, an O-D matrix was estimated. Comparison of actual link volumes from manual traffic count study and estimated link volumes from software is shown in Table below.

\begin{tabular}{|l|l|l|}
\hline $\begin{array}{l}\text { Road (One } \\
\text { direction) }\end{array}$ & $\begin{array}{l}\text { Actual Volume } \\
\text { (from traffic } \\
\text { counts) (vehicles } \\
\text { per day) }\end{array}$ & $\begin{array}{l}\text { Estimated } \\
\text { Volume(vehicles per } \\
\text { day) from CUBE }\end{array}$ \\
\hline $\begin{array}{l}\text { Bharathidasan } \\
\text { salai Road }\end{array}$ & 20833 & 18912 \\
\hline Bishop road & 17032 & 14992 \\
\hline $\begin{array}{l}\text { Puthur EVR } \\
\text { Road }\end{array}$ & 17480 & 17190 \\
\hline $\begin{array}{l}\text { Williams } \\
\text { Road }\end{array}$ & 9776 & 8528 \\
\hline $\begin{array}{l}\text { Sastri } \\
\text { Road }\end{array}$ & 13122 & 12910 \\
\hline $\begin{array}{l}\text { Lawsons } \\
\text { road }\end{array}$ & 17376 & 15093 \\
\hline
\end{tabular}

\subsection{Comparison of Traffic Volumes between Actual}

\section{and Estimated Volumes}

Samples of Obtained O-D matrix and Updated O-D matrix are shown below. The O-D matrix of 2013 obtained from traffic counts is almost 1.5 times the travel demand compared to the
O-D matrix obtained from traditional method and the validated results shows a RMSE of $6 \%$. Six percentage of error is an acceptable value as per state of art.

\begin{tabular}{|l|l|l|l|l|l|}
\hline $\mathrm{O} / \mathrm{D}$ & 1 & 2 & 3 & 4 & 5 \\
\hline 1 & 5 & 76 & 18 & 17 & 15 \\
\hline 2 & 76 & 9 & 101 & 69 & 55 \\
\hline 3 & 23 & 105 & 0 & 912 & 323 \\
\hline 4 & 21 & 72 & 878 & 0 & 154 \\
\hline 5 & 20 & 61 & 325 & 160 & 0 \\
\hline
\end{tabular}

Obtained O-D Matrix

\begin{tabular}{|l|l|l|l|l|l|}
\hline O/D & 1 & 2 & 3 & 4 & 5 \\
\hline 1 & 0 & 122 & 35 & 33 & 30 \\
\hline 2 & 121 & 0 & 159 & 111 & 90 \\
\hline 3 & 42 & 165 & 0 & 912 & 323 \\
\hline 4 & 39 & 116 & 1325 & 0 & 238 \\
\hline 5 & 38 & 98 & 494 & 248 & 0 \\
\hline
\end{tabular}

Updated O-D Matrix

\section{CONCLUSIONS}

The factors affecting travel demand in the study area was identified and incorporated in the model using appropriate network conditions to obtain a scenario specific seed O-D matrix. The seed O-D matrix obtained is proportional to the actual travel demand.

- The seed O-D matrix which is used as the base for updating the matrix is found to be having close proximity to the actual O-D matrix and also the traffic counts from the manual survey. The wards having maximum and minimum number of trips are similar in both seed and updated matrix.

- In this thesis a highly efficient transportation software CUBE has been used to generate the seed matrix using the traditional real world data and also to incorporate the link counts and update the matrix.

- Gradient descent approach helps in updating the O-D Matrix and hence travel demand estimation will be easier and effective. The feasibility of the developed program has been validated from the hypothetical networks.

\section{ACKNOWLEDGMENTS}

The authors wish to thank the Department of Civil Engineering, NIT Tiruchirappalli for their support and guidance. We also extend gratitude to The Municipal Corporation of Tiruchirappalli for their valuable information and data. 


\section{REFERENCES}

[1] Bera, S. and K.V.K Rao, "Estimation of origindestination matrix from traffic counts: the state of the art”, European Transport Journal, 49, 2011, pp.3-23.

[2] Aswathy, R., "Analysing The Relation Between Land Use and Travel Demand Using 3S Technology", M.Tech Thesis Report, NIT Trichy, 2011.

[3] Maneesha, M., "Estimation of Orgin-Destination matrix from link volume counts", M.Tech Thesis Report, NIT Trichy, 2010.

[4] Chinnu, A.J., "Estimation of Orgin Destination matrix from link volume counts using Bi level programming for Tiruchirappalli city", M.Tech Thesis Report, NIT Trichy, 2009.

[5] Noriega, Y. and Michael Florian, "Some enhancements of the Gradient method for O-D Matrix adjustment", Logistics and Transportation Research Centre, CIRRELT, Canada, 2009.

[6] Peterson, A. and L.T Lundgren, "An Heuristic Algorithm for Bi-level Origin Destination Matrix Estimation problem", Transportation Research, Part B, 41, 2008, pp. 339-354.

[7] Colson, B., P. Marcotte and G. Savard, "Bilevel programming: A survey", Annual Operations Research, 153, 2007, pp. 235-256.

[8] Ziyou, G., W. Jianjun, and S. Huijun, "Solution algorithm for the bi-level discrete network design problem", Transportation Research Part B, 49, 2005, pp. 479-495.

[9] Javier, D. and G. Francis, “An approach for estimating and updating Origin-Destination matrix based upon traffic counts preserving the prior structure of a survey matrix", Transportation Research Part B, 39, 2004, pp. 561-595.

[10] Maher, M.J., X. Zhang, and D.V. Vliet, "A bi-level programming approach for trip matrix estimation and traffic control problems with stochastic user equilibrium link flows", Transportation Research Part B: Methodological, 35, 2001, pp. 23-40.

[11] Yang, H., "Heuristic Algorithms for Bilevel Origin Destination Matrix Estimation problems", Transportation Research Part B, 29, 1995, pp. 231-242.

[12] Thomas, A. E. and F. B. Jonathan, "Algorithms For Nonlinear Bilevel Mathematical Programs", IEEE Transactions On Systems, Man, And Cybernetics, 21, 1991, pp. 83-89.

[13] Spiess, H., "A Gradient approach for the O-D matrix adjustment problem", Annual Report, EMME/2 Support Centre, Switzerland,1990

[14] Abrahamsson, T., "Estimation of Origin-Destination Matrices Using Traffic Counts - A Literature Survey", International Report, IIASA-98, 1988

[15] Cascetta, E. and S. Nyugen, "A unified framework for estimating or updating Origin-Destination matrices from traffic counts", Transportation Research Part B, 22, 1988, pp. 437-455.

[16] Speiss, H., "A maximum likelihood model for estimating Origin- Destination matrices", Transportation Research Part B, 21, 1987, pp. 395-412.

[17] Cascetta, E., "Estimation of Trip Matrices from Traffic counts and Survey data: A Generalised Least Square Estimator" Transportation Research Board-B, 18, 1984, pp. 289-299.

[18] L.G Willumsen, "Estimation of Origin-Destination Matrices Using Traffic Counts- A Literature Survey", Annual Report, Switzerland, 1978. 